\title{
A MODIFIED TECHNIQUE FOR CANNULATING THE RETE TESTIS OF THE BULL
}

\author{
J. K. VOGLMAYR, J. F. KAVANAUGH, * L. C. GRIEL, JR* \\ AND R. P. AMANN \\ Dairy Breeding Research Center, Department of Dairy Science, and \\ * Department of Veterinary Science, The Pennsylvania State University, \\ University Park, Pennsylvania 16802, U.S.A.
}

(Received 20th March 1972, accepted 31st May 1972)

The development of a technique for cannulating the rete testis permitted continuous collection of spermatozoa and fluid from the testis of conscious rams for up to 5 months (Voglmayr, Scott, Setchell \& Waites, 1967; Voglmayr, 1970). When this technique was employed on bulls, the flow of rete testis fluid began to decline 4 to 5 days after surgery and ceased by Day 11 (Voglmayr, Larsen \& White, 1970). Histological examination revealed that fibrous tissue had blocked the orifice of the catheter (J. K. Voglmayr, unpublished observations). Early cessation of flow was unusual in rams even if several attempts were required to insert the flexible catheter into the rete testis (J. K. Voglmayr, unpublished observations). This paper describes a modified technique for cannulating the bull rete testis using an instrument designed to minimize tissue damage and to facilitate insertion of the catheter.

The instrument, termed a 'catheter holder', was made from seamless, stainless steel tubing ( $1.168 \mathrm{~mm}$ i.d., $1.651 \mathrm{~mm}$ o.d.; 16 gauge needle) by milling a slit (LS, $0.6 \mathrm{~mm}$ wide) along its entire length of $4 \mathrm{~cm}$ and a short slit (SS, $6 \mathrm{~mm}$ long) at one end of the reverse side (Pl. 1, Figs and 1 and 2). A solid, curved extension of stainless steel (E, $0.7 \mathrm{~mm}$ diam., $5 \mathrm{~mm}$ long) which had a notch $(\mathrm{N})$ on its periphery near the tip, was soldered on the tube between the two opposing slits. Before surgery, a silicone rubber catheter (Voglmayr et al., 1967) was placed into the lumen of the catheter holder so that the tubular end of the holder engaged the cuff $(\mathrm{C})$ and the notch of the extension the lateral orifice $(\mathrm{O})$ of the catheter (Pl. 1, Figs 3 and 4).

Eight bulls (seven Holstein and one Guernsey; 2 to 6 years old) were secured by neck chain in a ventilated barn where they were exposed to natural daylight and ambient temperature.

For surgery, the animals were premedicated with atropine sulphate (about $0.044 \mathrm{mg} / \mathrm{kg}$ ) and restrained in right lateral recumbency on a tilt-table. Anaesthesia was induced with thiamyl sodium $(4.5$ to $5.0 \mathrm{mg} / \mathrm{kg})$ and maintained with Halothane administered with nitrous oxide-oxygen in a semiclosed circuit system. An incision, about $10 \mathrm{~cm}$ in length, was made through the anterior scrotum over the dorsal pole of the right testis about $2 \mathrm{~cm}$ lateral and parallel to the median raphe. Since the testis retracted when the tunica vaginalis was encountered, $10 \mathrm{ml} 2 \cdot 5 \%(\mathrm{w} / \mathrm{v})$ procaine hydrochloride were 
introduced into the cavum vaginale through a small opening in the tunica; the external cremaster muscle relaxed within $5 \mathrm{~min}$. After extending the opening in parietal tunica vaginalis, the visceral tunica was incised along the edge of the proximal caput epididymidis. The proximal caput was reflected from the testis by blunt dissection to isolate the bundle of efferent ducts so that two braided silk sutures (4-0) could be passed behind it. Using the sutures to immobilize the efferent ducts by traction, a puncture incision was made with a cataract needle into the sheath near the caput epididymidis and the needle was inserted 8 to $10 \mathrm{~mm}$ toward the rete testis. After enlarging the incision with dilators, the loaded catheter holder (Pl. 1, Fig. 4) was introduced into the depths of the incision. Using thumb forceps to exert pressure across the efferent duct bundle above the cuff of the catheter, the holder was withdrawn leaving the catheter in place (Pl. 1, Figs 5 and 6). The traction sutures were tied, transfixing the catheter above its cuff and occluding all the efferent ducts.

The free end of the catheter was directed through a puncture at or near the reflection of the caput epididymidis adjacent to the efferent ducts and the epididymis was secured in its normal position with interrupted sutures of 0 medium chromic catgut. The catheter was exteriorized by puncture incisions through the posterior tunica vaginalis and scrotum approximately at the level of the dorsal pole of the normally descended testis. After the anterior incisions were closed by means of two layers of interrupted sutures (medium chromic catgut, 1-0), the skin margins were united with a continuous vertical mattress suture of heavy Vetafil (Bengen) and covered with Scan spray bandage (Johnson \& Johnson). The exposed free end of the catheter was secured in the screw-cap of a receptacle elbow by placing a split polyethylene washer $(6 \mathrm{~mm}$ diam.) around the catheter above its terminal cuff. The elbow had been fabricated by fixing the side of a screw-cap to Dacron mesh $(5 \times 8 \mathrm{~cm})$ and then forming a hollow elbow from Silastic Medical Adhesive Type A (Dow Corning Corp.). It was secured on the posterior scrotum with two interrupted retention sutures (Amann, Hokanson \& Almquist, 1963). Bacterial contamination was controlled by immersion of the exposed catheter and the screw-cap for $30 \mathrm{~min}$ in $0.6 \%$ Tego 51/15DL (Goldschmidt A.-G., Essen) followed by rinsing with sterile $0.9 \% \mathrm{NaCl}$ before the gas-sterilized polyethylene receptacle was attached.

Four preparations in three bulls were patent for 16 to 43 days. Except for some fluctuations during the first 2 days, the rate of fluid secretion was steady for the first 12 days of collection (Text-fig. 1). Excluding data for the fourth cannulation which was performed after unilateral castration, the mean $( \pm$ S.E.) flow of rete testis fluid in three entire bulls was $44 \cdot 4 \pm 2 \cdot 12 \mathrm{ml} /$ day for the period of 'normal flow'. This should be contrasted with a volume of some 0.6 to $1.4 \mathrm{ml}$ of epididymal semen recovered daily from the cannulated vas deferens or the corrected (see Amann, 1970) daily volume of $4.68 \pm 0.44 \mathrm{ml}$ of ejaculated semen collected by an artificial vagina for 13 to 25 consecutive days before surgery. The concentration of spermatozoa in rete testis fluid averaged 50.6 $\pm 3.49 \times 10^{6}$ cells/ml during the first 7 days following surgery. However, after 7 to 12 days, the sperm concentration markedly declined but the fluid continued to flow at the same or at a slowly diminishing rate (Text-fig. 1). The daily output of $2 \cdot 29 \pm 0 \cdot 14 \times 10^{9}$ spermatozoa by the testis was within the range reported 
PI..\IE !
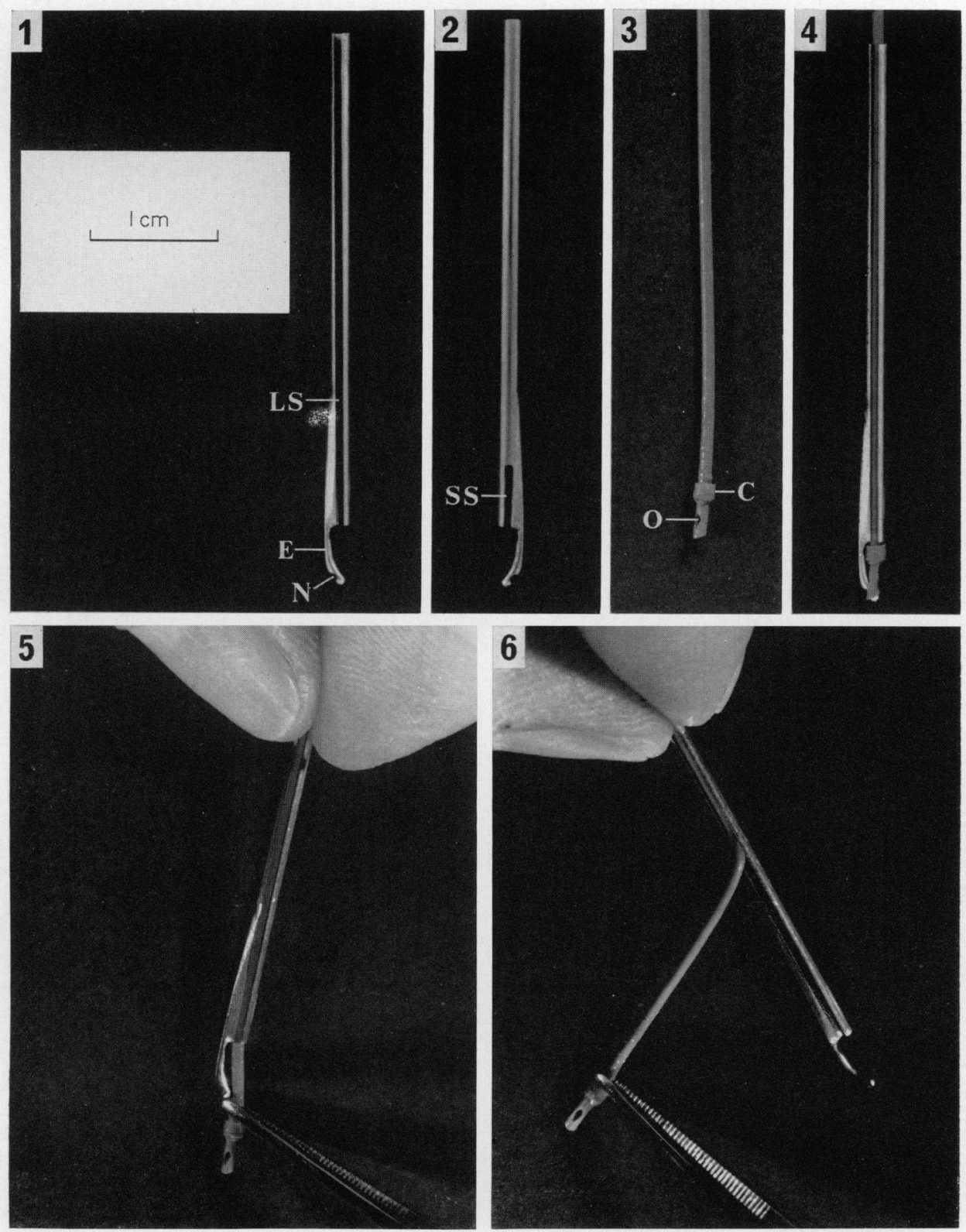

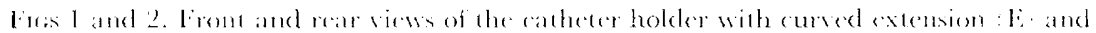

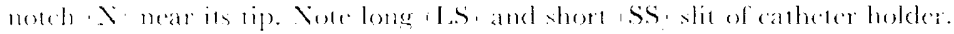

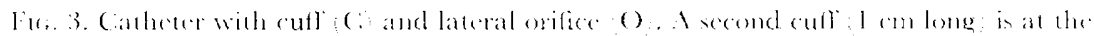
cominal enel of the 32 an long catherer.

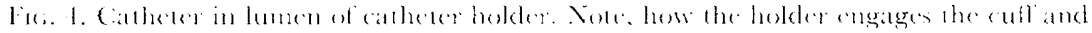
lateral arilice al the catherers.

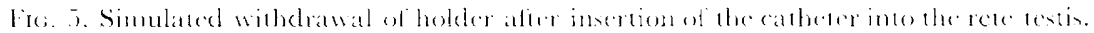

lin. fi. Remenal of catheren holdere uning in long slis. 
previously for bulls (Voglmayr et al., 1970; Amann, Kavanaugh \& Griel, 1970). However, one-half the daily sperm output in semen ejaculated by these three bulls before surgery was $2.89 \pm 0.95 \times 10^{9}$ cells. Thus, the observed sperm output by the cannulated testis or in ejaculated semen may not be an accurate mirror of normal sperm production.
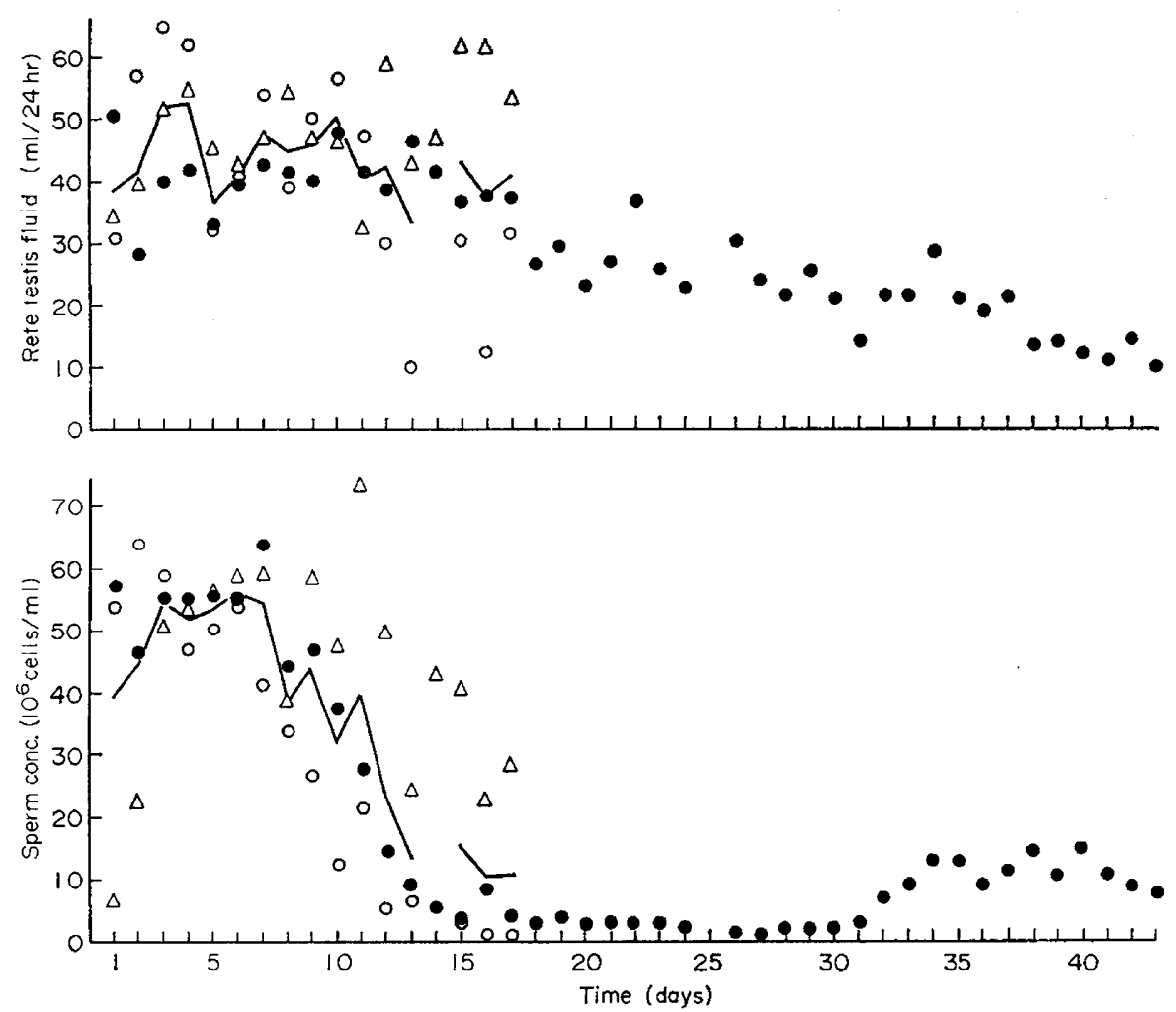

TEXT-FIG. 1. Secretion of rete testis fluid by the bull testis and concentration of spermatozoa in the fluid. Symbols denote collections from single testes of three entire bulls and the line represents the mean. In two bulls $(0, \bullet)$, the contralateral vas deferens was cannulated concurrently; no measurements were made on one of these bulls $(O)$ on Day 14 , and none were made on the other bull $(\bullet)$ on Day 25 . In one bull $(\Delta)$, the contralateral testis was cannulated 60 days after unilateral castration and the mean ( \pm S.D.) daily output of fluid was $62.8 \pm 11.2 \mathrm{ml}$ containing $29.5 \pm 13.5 \times 10^{6}$ spermatozoa/ml for 18 consecutive days.

Less than half the cannulations were performed successfully in this experiment. Nevertheless, the use of the catheter holder has greatly facilitated the technique described and the preparations were patent for much longer periods of time than have previously been reported.

The research upon which this publication is based was performed pursuant to Contract NIH-NICHD-69-2137. Authorized as Paper No. 4152 in the journal series of the Pennsylvania Agricultural Experiment Station. 


\section{REFERENCES}

Amann, R. P. (1970) Sperm production rates. In: The Testis, Vol. I, p. 433. Eds. A. D. Johnson, W. R. Gomes and N. L. VanDemark. Academic Press, New York.

Amann, R. P., Hokanson, J. F. \& Almquist, J. O. (1963) Cannulation of the bovine ductus deferens for quantitative recovery of epididymal spermatozoa. 7. Reprod. Fert. 6, 65.

amann, R. P., Kavanaugh, J. F. \& Griel, L. C., JR (1970) Cannulation of the bull rete testis and vas deferens. J. Anim. Sci. 31, 216.

Vogrmayr, J. K. (1970) Comparative studies of testicular and ejaculated ram and bull semen. Ph.D. thesis, University of Sydney.

Voglmayr, J. K., LARSEN, L. H. \& White, I. G. (1970) Metabolism of spermatozoa and composition of fluid collected from the rete testis of living bulls. F. Reprod. Fert. 21, 449.

Voglmayr, J. K., Scott, T. W., Setchell, B. P. \& Waites, G. M. H. (1967) Metabolism of testicular spermatozoa and characteristics of testicular fluid collected from conscious rams. F. Reprod. Fert. $14,87$. 